whether the wearing of a pair of spring-soled boots, such as a recent inventor has suggested, would add boots" have an outer sole, which is pivote to the one made on the boot just below the ball of the foot A strong spiral spring is fitte between the two at the A strong spiral spring is fitted between the two at the
heel. To see a whole regiment charging a position wearing these boots, and bounding over the ground like kangaroos or wallabys, would indeed be a remarkable sight. The boring projectile here illustrate appears a somewhat more plausible creation, but the inventor can have very little realized the immense force and velocity with which modern projectiles strike their objective. Inlagine a shot weighing over 800 pounds traveling over 2,000 feet a second, and striking with an energy of thousands of tons to the square foot, pausing in its career to carry out the comparatively slow process of boring through an armor plate like a gimlet! The Cullen ball-bearing gun is another extraordinary attempt to improve modern artillery. The sketch of its cross section will enable the reader to understand the idea, which, put shortly, is to substitute for the ordinary grooves of a rifled gun, through which the soft metal of the diving band has projectile, a series of spiral rows of steel balls. These lie in grooves of a circular section cut in the sides of the bore of the gun, into which about one-twentieth of their diameter projects, so that while a spiral motion is given to the projectile, its progress is not re tarded by friction, but rather accelerated. How the inventor is going to prevent the waste products of the combustion of the propelling charge from being driven into the interstices between the steel balls and jamming them all together, so that they revolve with difficulty, does not appear. The absurdity of the scheme was exposed by the Scientific American several years ago. Another remarkable invention, which like the preceding one, by the way, hails from America, is a cannon that takes completely to pieces. It consists of a series of strong steel disks which fit over the inner tube, which is, of course, rifled internally. $\mathrm{Ex}$ ternally it tapers slightly, so that it is bigger and thicker at the breech end. The disks slide down on this tube in their proper order, the central ones having projections to form the trunnions of the piece, and are screwe tight up by means of four rods and nuts fitting into a massive framework at either end of the gun. The rear one of these carries the breech-closing gun. The rear one of these carries the breech-closing by the invention of smokeless powder, and now in ventors are trying to do away with the noise of the explosion into the bargain. This was effected in ancient days, according to an Arab writer, by the "powder which explodes without sound," made at El Meidarin, the ashes of human bones taking the place of charcoal. The making of this propellent is now, at any rate, a lost art, but the same object is, to a certain extent, attaine in otlier ways. Col. Humbert. of the French army, has invented a species of tube which, affixed to the muzzle of a field piece, prevents either flash or sound, while a rifle invented in America has a big cartriage containing water, which interposes between the bullet and the powder charge in its base. This is suppose to regulate the escape of the powder gas, and so minimize the report without diminishing the force and velocity with which the projectile leaves the barrel. The great addition which this system would make to the weight of the ammunition is quite
enough to put the weapon out of court for military purposes.

With this quite recent triumph of impracticable in vention we must bring our short review of extraordinary military contrivances to a close. Myriads of other warlike "freaks" might be cited, but we have quote enough to make it obvious that, as far as they are concerned, the process of "beating our swords into plowshares" might begin without in any way bringing plowshares" might begin without in any way bringing
in the epoch of universal peace. The practical weapons that would remain are amply sufficient to provide
"battle, murder, and sudden death" for many centuries to come.

Beans are at present cleane by hand work, which is not only slow, but unsatisfactory. The beans are scattere on a belt which passes before a row of girls, and stones, dirt, and other objectionable particles-are picked out. In this way the cleaning capacity of each girl is between three and five bushels per hour. A machine for this purpose has been recently invented by Robert A. Little, of Lockport, N. Y., which perf rms the operation in a much superior and more cconomical manner. In this process the beans fall from a height into a shaking hopper, and here the chaff and lighter material are removed, after which the mass is transferre to a belt, where the foreign particles are carried one way and the whole and perfect beans are diverted to a compartment, where they fect beans are diverte to a compartment, where they only removes all trace of dust and dirt, but gives the beans a high polish, which improves their selling qualities.

\title{
THE MICROPHOTOSCOPE-AN APPARATUS FOR
} EXAMINING MINUTE MAPS.

The importance of an efficient intelligence service in ime of war will be readily appreciated by anybody. The most important element in similar service is a suitable stock of reliable maps, but even in case firstclass maps are available, many drawbacks will be experienced, especially at night and during storms and rain, in using ordinary maps of the Etat Major; and the same may be said of maps intended for the use of tourists and sportsmen. The folding of large maps is moreover extremely inconvenient, and results in rapid wear and tear of the same.

A very suitable device to obviate the above inconveniences has been invented by Dr. Otto H. F. Vollbehr, of Halensee-Berlin, in the shape of the microphotos cope. Though not doing away entirely with the necessity of ordinary maps, this device will afford mosî welcome com plement to them. With this aid $\mathrm{m}$ croscopic transpar encies $4 \times 5$ centi meters $(1.574 \times 1.968$ nches) in size are sed in place of
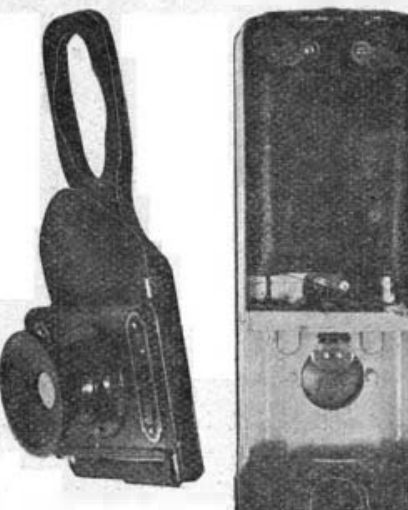

THE LENS AND SLIDE HOLDER OF THE MICRO-
PHOTOSCOPE, represent a map of the Etat Majo drawn to the scale of $1-100,000$. They are inserte between two glass bin ng plates, so as to form a lantern lide. In front of the transparency there is a lens capable of being a justed for any eye by turning it either to the left or right. No other tion with the be used in conn is fitte in a small frame susceptible of a vertical and horizontal dis placement, so as to enable any point of the transpa ent map to be brought immediately in front of the eye 175 square kilometers (67.56 square miles) being in spected with each position of the lens. The minute map is divided into squares at distances of 2.5 kilo meters ( 1.55 miles) each, the squares being numbere horizontally at the top of the map and marked with letters in a vertical direction, thus enabling any given point to be traced readily. The slides fit loosely in the holder and they can be exchanged at a moment's notice whenever another map is to be examine

If the lens is used in the daytime, it should be held with the handle in front of the eye, when an intensely illuminated image of the map will be obtained, so that even the smallest lines and most minute marks will be readily distinguished. For use at night an especially designed illumination box is added, including small

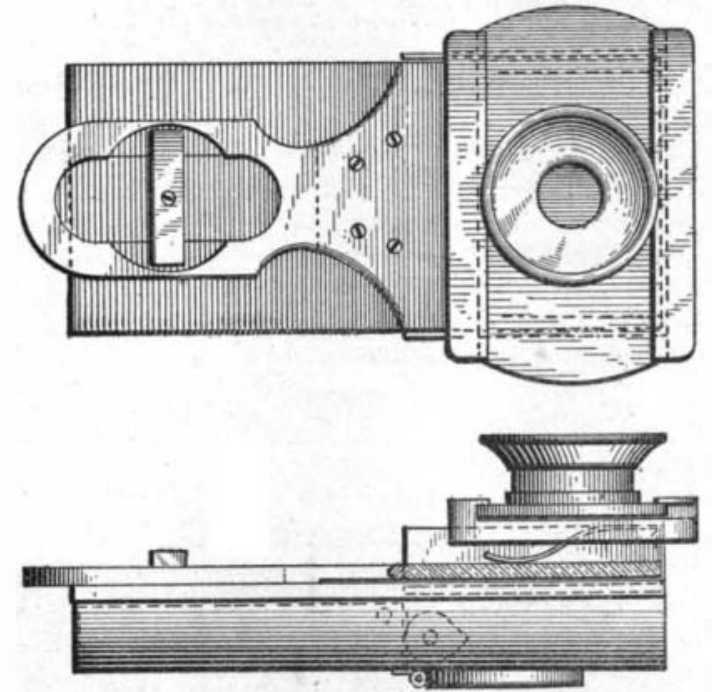

TOP AND SIDE VIEWS OF THE LENS MOUNTING.

electric light similar to the familiar "ever-ready" lamps. This box can be attache to the back of the apparatus, where it is held in place by small clips. This lamp illuminates the transparent map about as intensely as does daylight, and thus the lamp can be used in dim weather if more light is needer.

The latest type of apparatus has been arranged for keeping the button pressed down permanently, thus avoiding a continual pressure on the same. A reserve. battery is provided for supplying the amount of light require for twelve hours' uninterrupted service of the glow lamp, this battery being worn like the cover of a field glass. The transparencies have recently been

\section{A Novel Photometer.}

The numerous attempts so far made to utilize the luminous sensitiveness of selenium for the construc tion of a suitable photometer have now for the first ime been crowned with success, in connection with novel selenium photometer brought out by a Mayence constructor, which is quite independent of the inertia of the selenium, the temperature of the air, and the loa on the selenium cell, as well as of all other fac tors disturbing the sensitiveness of the selenium. The slow alteration undergone by the selenium cell in course of time is doubtless without any influence on the tests. The accuracy insure in using this apparatus greatly exceeds the accuracy afforded by any similar photometrical process, while the tests are carried out more rapidly and without any difficulty

The novel principle used in constructing this photometer consists in throwing a selenium cell in a rapid alternation from the range of a standard lamp into the range of the lamp to be measured, the resulting current oscillations being ascertained by suitable in struments. As soon as the oscillations of an index are discontinued, the illumination produced on the cell by both of the illuminants is found to be equivalent.

The apparatus includes two mirrors lighted by the two illuminants respectively, while a selenium cel rapidly oscillating between two given positions is lighte alternately by either. The index of an ammeter oscillates in accordance with the fluctuations in illumination thus produced, and the instrument should be displace until these oscillations are found to cease, thus showing the equivalence of the illuminations due to either lamp, when their respective distances from the photometer will, according to a well-known rule, give the luminous intensity of the lamp to be tested in terms of the standard lamp.

This photometer is intended in the first place for the comparison of illuminants of the same class. One good point of the apparatus is the rapidity with which measurements are carried out. Moreover, the eye is put to far less strain than in any other method connection with scientific investigation into the hitherto unknown mechanism of the sensitiveness shown by selenium in regard to light. Our present knowledge does not go far beyond the fact that two of the allotropic modifications of selenium, and especially the light-gray brittle variety, show a decrease in electrical resistance as soon as they are exposed to an illumination, this decrease being dependent on the luminous intensity of the latter.

As regards the influence of considerable differences in color between the two illuminants, selenium seems to behave very well with the luminous sensitiveness of the eye in regard to the same color. It thus seems likely that no errors worth mentioning will be made in practical tests, and it is surmise that the retina of our eye perceives in the same way as selenium, while such differences as have been found from time to time are attributable to the absorption of rays by the liquid and other membranes of the eye. A suitable compensation could thus be obtained by inserting in front of the selenium cell an optical medium equivalent to the substances lying in front of the retina.

\section{Free Winter Course in Dairy Farming.}

The Massachusetts Agricultural College offers without charge for tuition a general course of instruction in the management of a dairy farm and in dairy operations. This course begins January 2 and continues ten weeks. It is open "to all citize

Students taking this course enjoy the great advantage of a systematic, thorough, and short course of training under recognized experts. The subjects taken up are soils, manures, fertilizers, and crops, the breeds and breeding of dairy stock, the feeding of dairy animals, stable construction and sanitation, prevention and treatment of the common diseases of stock, dairy products, their general characteristics and the laws of milk production, pasteurization, elementary botany and entomology, and general horticulture. Students receive careful training and extensive prac-
tice in the use of separators, making the Babcock test, ice in the use of separa

All wide-awake communities are demanding better dairy products. Students taking this course learn how to make the necessary improvements in methods of production. The demand for farm superintendents is great, but only up-to-date superintendents are wanted. Those taking this course are able to learn the latest methods. Any one desiring information concerning the course should address Prof. William P. Brooks, Amherst, Mass.

The largest marine gasoline engine in the world has been shipped from Baltimore to Russia. It is of 1,600 horse-power, and is one of four ordere by the Czar's government, at a cost of $\$ 100,000$, to go into Lake submarine torpe boats. 